\title{
Bird-pollinated Macaronesian Lotus (Leguminosae) evolved within a group of entomophilous ancestors with post-anthesis flower color change
}

\author{
Dario I. Ojedaa ${ }^{\mathrm{a}, *}$, Arnoldo Santos-Guerra ${ }^{\mathrm{b}}$, Felicia Oliva-Tejera ${ }^{\mathrm{c}}$, Alfredo Valido ${ }^{\mathrm{d}}$, \\ Xinxin Xue ${ }^{\mathrm{a}}$, Aguedo Marrero ${ }^{\mathrm{c}}$, Juli Caujapé-Castells ${ }^{\mathrm{c}}$, Quentin Cronk ${ }^{\mathrm{a}}$ \\ a The Biodiversity Research Center and Department of Botany, University of British Columbia, 6804 SW Marine Drive, Vancouver V6T 1Z4, Canada \\ b Unidad de Botánica-ICIA, Puerto de la Cruz, Canary Islands, Tenerife, Spain \\ 'Jardín Botánico Canario "Viera y Clavijo"- Unidad Asociada CSIC, Cabildo de Gran Canaria Las Palmas, Gran Canaria, Spain \\ d Department of Integrative Ecology, Estación Biológica de Doñana (EBD-CSIC), C/Américo Vespucio s/n, La Cartuja , 41092 Sevilla , Spain
}

Keywords:

Anthocyanin

Flavonol

Flower color change

Bird pollination

Lotus

Canary Islands

\begin{abstract}
A B S T R A C T
We analyzed the evolution of red/orange flowers in four putatively bird-pollinated species of Macaronesian Lotus, with the aim of investigating whether this floral trait evolved from a similar trait found in some entomophilous Lotus species, namely the ability to modify flower color to red after anthesis. First, we mapped the ability to modify flower color in this group on a well-resolved and densely sampled phylogenetic tree of the Macaronesian Lotus. Secondly, we determined differences in light reflectance and pigment composition between petals of (1) prechange and postchange flowers in bee-pollinated species and (2) between bee and putatively bird-pollinated species. Post-anthesis flower color change evolved three times within Macaronesian Lotus, and putatively bird-pollinated species evolved within a clade with this ability to change flower color to red after anthesis. The evolutionary transition to red/orange flowers in the putatively bird-pollinated species involved biochemical changes similar to those of the developmental transition to red postchange flowers. In both cases there are changes in the composition of flavonols and anthocyanidins within the same metabolic pathways, especially in the cyanidin branch of pigment production, but not the activation or inactivation of additional branches of this pathway. Postanthesis color change in Lotus, from yellow to red, is thought to be an adaptation to reduce bee visits to already pollinated flowers. Our results are consistent with the hypothesis that constitutive red coloration for bird-pollination evolved from facultative red flower color change in Lotus. As red post-anthesis coloration is widespread in plants, this may possibly represent a widespread exaptive mechanism for the evolution of bird pollination.
\end{abstract}

\section{Introduction}

Oceanic islands offer excellent environments for the study of evolutionary and biogeographic processes (Soja, 1982; Whittaker and Fernández-Palacios, 2007). They are particularly valuable for the study of long distance dispersal, speciation and adaptation, as their ecosystems are in general biologically simpler than their continental counterparts. Like other oceanic islands, the Macaronesian archipelagoes (including Azores, Madeira, Canary, Salvage and Cape Verde islands) offers outstanding examples of endemism and adaptive radiations, e.g. Echium (García-Maroto et al., 2009), Crambe (Francisco-Ortega et al., 2002), Aeonium (Jorgensen and Olesen, 2001; Olesen et al., 2012), Sonchus (Kim et al., 1996), Tolpis

\footnotetext{
* Corresponding author. Tel.: +1 6048270324.

E-mail address: dario.alayon@gmail.com (D.I. Ojeda).
}

(Mort et al., 2003), Cistus (Guzmán and Vargas, 2005) and Campanulaceae (Olesen et al., 2012), among others. Many of these endemics show convergent evolution of insular woodiness and other morphological plant traits.

One such example of parallel evolution is the repetitive convergence of a set of floral traits (i.e. a pollination syndrome), including copious dilute nectar, lack of scent, robust flowers, and red/orange colors, apparently as adaptations to attract opportunistic passerine birds as pollinators (Vogel et al., 1984; Olesen, 1985; Dupont et al., 2004; Valido et al., 2004; Valido and Olesen, 2010). In these islands, floral adaptations to attract opportunistic passerine birds have been proposed in at least 13 endemic species from six plant families (Valido et al., 2004), which represent around $0.4 \%$ of the native flora. However, the role of these passerine birds as effective pollinators has been conclusively demonstrated in only two species, Isoplexis canariensis (Plantaginaceae) and Canarina canariensis (Campanulaceae) (Rodríguez-Rodríguez and Valido, 2008, 2011; Ollerton 
Table 1

Differences in floral traits between bee- and the putatively bird-pollinated species of Macaronesian Lotus. Although in some examples floral scent is lost in the transition to bird pollination, in this case both the putatively bird-pollinated species and their closest bee-pollinated relatives appear to be unscented (at least for human detection).

\begin{tabular}{lll}
\hline Floral trait & Bee-pollinated & Bird-pollinated \\
\hline Color & Yellow & Red/orange \\
Shape & Standard large Keel & Standard small Keel \\
& small & large \\
Size & Small & Large \\
Orientation & Horizontal & Erect \\
Longevity & Short & Long \\
Nectar volume & Low & High \\
Nectar composition & Sucrose & Hexose \\
Nectar concentration & High & Low \\
Conical cells in dorsal petal & Present & Absent \\
\hline
\end{tabular}

et al., 2009; Rodríguez-Rodríguez et al., 2013). Despite the presence of many species with a bird pollination syndrome, there is as yet little understanding of the mechanisms by which all these floral adaptations evolved in such diverse plant lineages in a geographic region that lacks specialist nectarivore birds (e.g. sunbirds and hummingbirds) (Valido et al., 2002, 2004).

Flower color modifications associated with bird pollination have been well characterized in other plant groups (Cronk and Ojeda, 2008; Rausher, 2008). To date most studies at the biochemical level have involved floral transitions to hummingbird pollination while flower color transitions in oceanic island environments, under the selection of opportunistic passerine bird visitors (rather than specialist nectar feeding species) is largely unexplored. Here we address the evolution of red/orange flowers in the "rhyncholotus group" of Macaronesian Lotus. The majority of the nearly 40 Macaronesian species within this genus have the usual floral traits (such as yellow petals) found in continental Lotus, as in the widespread $L$. corniculatus, and which are strongly associated with bee pollination (Hohmann et al., 1993; Proctor et al., 1996). Floral traits associated with bird pollination are present in four species within this genus (all in the Canary Islands) and the transition from their closest bee-pollinated ancestors (Allan et al., 2004; Degtjareva et al., 2006; Ojeda et al., 2012a,b) involved not only a change from yellow to red/orange flowers, but several additional floral traits, including changes in flower size, shape, orientation, flower longevity, petal micromorphology, as well as nectar composition and concentration that is characteristic of bird pollinated plants (Olesen, 1985; Dupont et al., 2004; Valido et al., 2004; Ollerton et al., 2009; Ojeda et al., 2012a,b) (Fig. 1A and B and Table 1).

Rhyncholotus group species are very rare in the wild so the only direct observations of floral visits by birds, Phylloscopus canariensis (Phylloscopidae), are from cultivated plants of Lotus berthelotii from Tenerife, Canary Islands (Stelzer, 2005; Ollerton et al., 2009). We have observed honey bees and ants visiting flowers of this group (Ojeda and Santos-Guerra, 2011), but they do not behave as legitimate pollinators. Further studies are needed to determine the effectiveness of passerine birds in pollinating these species. Interestingly, pollination interactions with lizards have also been observed in Lotus maculatus (Siveiro and Rodríguez-Rodríguez, 2012) and in L. berthelotii (Ollerton et al., 2009) and Lotus maculatus (S-RR 2012) (Ollerton et al., 2009). While noting that the circumstantial evidence for bird pollination is very strong we nevertheless refer to this group as "putatively bird-pollinated" because of the lack of direct evidence of pollen transfer by birds. Despite the marked differences in flower morphology between the four putatively bird-pollinated species and their closest bee-pollinated ancestors, the bird pollination syndrome in Lotus evolved relatively recently within the last 2 Mya (Ojeda et al., 2012a,b).
One striking characteristic of some bee-pollinated Macaronesian Lotus species is their ability to modify flower color after anthesis (Sandral et al., 2006). Flower color change is not unique to the Macaronesian Lotus species, as this phenomenon has been observed in other continental Lotus species (Weiss, 1995). Observations in other groups suggest that color change is cued by pollination, although unpollinated flowers will also change color, although more slowly (Jones and Cruzan, 1999). We have been able to make extensive observations of color change, both of wild plants in the field in the Canary Islands, as well as of cultivated plants in nurseries and gardens. Flowers after anthesis may modify coloration from yellow/cream (prechange) to brown, pink, orange, purple or red (postchange) depending on the species (Fig. 1D-H) In this study we investigate first whether the four putatively birdpollinated Lotus evolved in lineages with the capacity to modify flower color after anthesis and second, the pigment modifications involved in the transition. In particular we wish to answer the following questions: (1) Is the ability to modify flower color associated with the evolution of red/orange flowers in this group? (2) Are prechange and postchange flowers likely to be perceived differently by pollinators in bee-pollinated species? Similarly, (3) are the putatively bird-pollinated flowers likely to be less discernible by insects than bee-pollinated flowers from the foliage background? (4) What were the modifications in pigment composition and expression of anthocyanin genes during the evolutionary transition in flower color and how does this compare with developmental post-anthesis flower color change? The answers to these questions will then be used to discuss the more general hypothesis that developmental flower color change is a pre-adaptation for the evolutionary transition to bird pollination syndrome.

\section{Materials and methods}

\section{Reconstruction of flower color change}

Color change was coded as a binary character (absence and presence of flower color change) and the evolution of this trait was mapped on a maximum parsimony phylogenetic tree of the group based on four gene regions (ITS, Cytochrome B6, trnH-psbA and $m a t K$ ) (Ojeda et al., 2012a,b). The phylogenetic analysis analysis gave 451 nearly identical equally parsimonious trees, and for the mapping analysis we selected one of these at random.

Flower color modification after anthesis was analyzed using parsimony (DELTRAN) as implemented in MacClade 4.0 (Maddison and Maddison, 2005). Ancestral state reconstruction was carried out using Mesquite (Maddison and Maddison, 2011). Flower color change was recorded for each species based not only on our own field observations, but also on cultivated plants in botanical gardens (Jardín de Aclimatación de la Orotova and Jardín Botánico Canario "Viera y Clavijo"), and on plants cultivated at the University of British Columbia (UBC) glasshouses. For those species that were neither cultivated nor observed in situ in the field, flower color was obtained from the literature (Monod, 1980; Mader and Podlech, 1989; Brochman et al., 1997; Jardim and Francisco, 2000; Bramwell and Bramwell, 2001; Sandral et al., 2006).

\section{Measurement of petal reflectance spectra}

In order to infer the insect visual receptors likely to be stimulated by each flower color, we measured the reflectance of petals of different flower colors. Petal reflectance was measured in situ using fresh collected flowers. Measurements were taken using a portable spectrophotometer (Ocean Optics USB-2000; Duiven, 

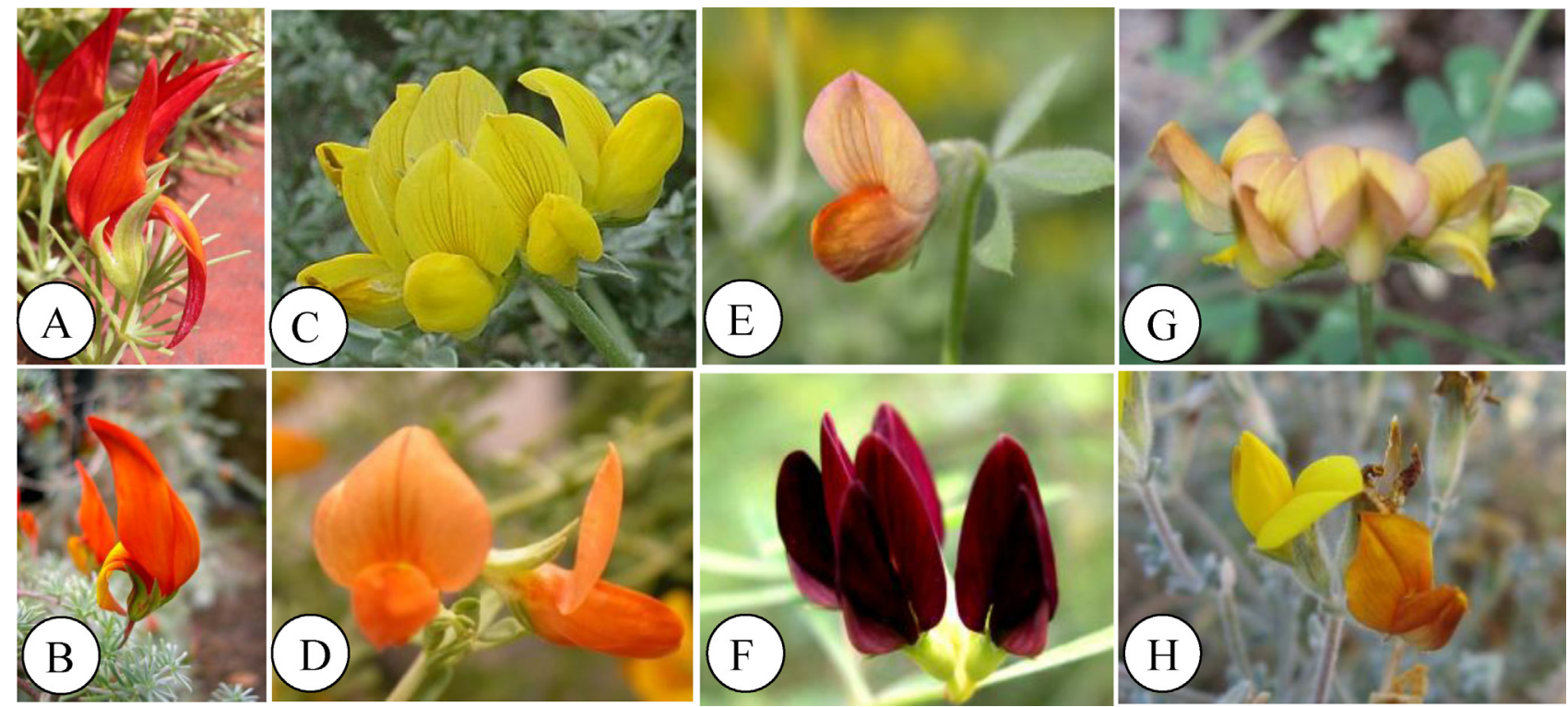

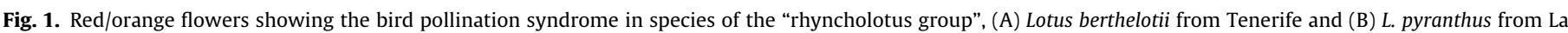

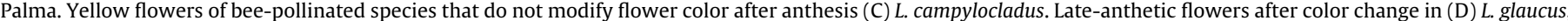

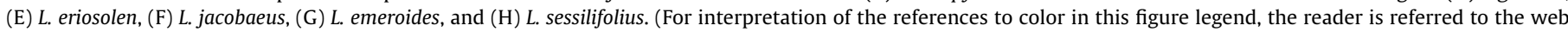
version of the article.)

Photo credits: I. Ojeda and F. Oliva-Tejera.

The Netherlands) connected to Deuterium-Halogen DH-2000 lamp (DT-MINI-GS-2; Ocean Optics). Reflectance was measured as the proportion of a standard white reference tile (WS-1-SS; Ocean Optics). We used a coaxial fiber cable (QR-400-7-UV-VIS-BX; Ocean Optics) for all measurements and held the distance between the sample and the measuring probe constant. The angle of illumination and reflection was fixed at $45^{\circ}$. Data were processed with SPECTRASUITE software (version 1.0; Ocean Optics) and calculated in 5-nm-wide spectral intervals over the range of $300-700 \mathrm{~nm}$. The three types of petals were measured separately on the side naturally exposed to pollinator vision (adaxial side of the dorsal petal, and abaxial side of lateral and ventral petals). All measurements were taken five times on the same section of the petal (middle part) for each individual, and the averages of these measurements were used to estimate the reflectance graph for each species. We measured between 5 and 10 petals for each species collected from different individual plants. Overall, 19 species were analyzed, including all four putatively bird-pollinated species, five yellow bee-pollinated species that do not change color, and 10 beepollinated yellow/cream species that change color after anthesis (measured both before and after the color change) (Table S1). The species included represent all postchange flower colors reported in this group, except pink and brown, which were not available for this study.

Supplementary material related to this article found, in the online version, at http://dx.doi.org/10.1016/j.plantsci.2004.08.011.

Reflectance graphs of each species were later classified according to their correspondence to action spectra of the four visual receptors found in pollinating organisms (UV, blue, green and red) (Chittka et al., 1994).

\section{Pigment extraction and composition analysis}

In order to determine the type of pigments produced in the flowers of each species and their modifications during pollination shifts, the three types of petals (dorsal, lateral and ventral) were separated from the rest of the flower and dried in silica gel. Pigments were extracted from petal samples $(20 \mathrm{mg})$ with an extraction buffer $\left(\mathrm{MeOH} / \mathrm{H}_{2} \mathrm{O} / \mathrm{AcAc}\right)$ and later treated with $\mathrm{HCl} 2 \mathrm{~N}$ at $100{ }^{\circ} \mathrm{C}$ for $30 \mathrm{~min}$ (Shimada et al., 2005). Samples dissolved on the same extraction buffer were injected via infusion into an LC Agilent 1100 series light chromatograph (LC-MS) with a LC7MSD trap XCT Plus. Two replicates from different individuals were analyzed for the focal species ( $L$. sessilifolius and $L$. berthelotii) in order to assess individual variation, but the remaining species were analyzed only in one individual, as the individual variation in pigment composition was minimal.

Pigments were identified using retention times of a mixture of six anthocyanin standards (cyanidin, peonidin, pelargonidin, petunidin, delphinidin and malvidin; Chromadex, Irvine CA) and three flavonols (quercetin, kaempferol and isorhamnetin; Sigma-Aldrich Co., St Louis, MO) prepared and analyzed under similar conditions. In total 20 species were analyzed, representing all flower colors reported in the bee-pollinated group. This sample included five yellow bee-pollinated species that do not modify flower color after anthesis and nine yellow/cream bee-pollinated species that change flower color after anthesis (both flower colors, i.e. prechange and postchange, were measured for each species). Our data set also included the four putatively bird-pollinated species and two species from section Lotus, the model legume L. japonicus and L. filicaulis, the latter a species that changes flower color after anthesis from yellow to red (Table S2).

Supplementary material related to this article found, in the online version, at http://dx.doi.org/10.1016/j.plantsci.2004.08.011.

The relative amount of each pigment was calculated from the area under the peaks in the MS spectra for each pigment identified using the LC/MSD trap software 5.2. The resulting data were used to establish which branches of the anthocyanin pathways were active, and to determine pigment pathway alterations during transitions of flower color within the bee-pollinated group (prechange vs. postchange) and between the bee- and putatively bird-pollinated species. 
Determination of the anthocyanin pathway branches active in Macaronesian Lotus

In order to further explore the activity of the anthocyanin pathway, and its different branches in this group during flower color transitions, we analyzed the expression of six structural genes of the flavonoid pathway using semi-quantitative reverse transcriptase PCR (RT-PCR). Gene expression comparisons in mature flowers (stage 13) at two sampling points (prechange and postchange when applicable) were carried out in five species: Lotus japonicus (which does not change color), its close relative Lotus filicaulis (Lotus section Lotus), L. sessilifolius var. pentaphyllus (section Pedrosia, closely related to the putatively bird-pollinated group, and with red postchange flowers), and two species from the putatively bird-pollinated ("rhyncholotus group"): L. berthelotii (with red flowers) and $L$. maculatus (yellow/orange flowers). For the focal species, $L$. berthelotii, L. maculatus and $L$. sessilifolius, we analyzed two replicates for each species from a pool of flowers from the same individual. All flower tissue was collected between 9:00 am and 11:00 am on the same day, immediately placed in liquid nitrogen and stored in $-80^{\circ} \mathrm{C}$ until further RNA extraction. All plants of the five species for this study were cultivated at the University of British Columbia (UBC) experimental glasshouse under similar conditions $\left(20-25^{\circ} \mathrm{C}\right)$ in pots of $10-20 \mathrm{~cm}$ in diameter and were more than 6 weeks old when flowers were collected for analyses. All species were propagated from seeds, except L. maculatus and L. berthelotii, which were purchased from commercial nurseries in Vancouver, Canada. They were grown under the same environmental conditions as the three bee-pollinated species mentioned above, except for the provision of a vernalization period of 30 days in order to induce flowering. Seeds of L. sessilifolius var. pentaphyllus were collected from the field in Playa San Juan Guía de Isora, Tenerife in 2008. Flower material was also collected from cultivated plants of $L$. berthelotii and L. maculatus in the "Jardin Canario Viera y Clavijo" following the procedure described above. For those species with a flower color change, RNA was extracted from the same developmental stage (stage 13) when flowers are just open and without color changes (prechange) and also just after flowers commence visible color modification (postchange). Details of the floral developmental stages are published elsewhere (Ojeda et al., 2012a,b). Each type of petal (standard, wings, keel) was collected and analyzed separately in all the five species described above.

In addition, two earlier developmental stages (stages 10 and 7; Ojeda et al., 2012a,b) were analyzed for two species, $L$. japonicus and $L$. berthelotii with the purpose of characterizing the early gene expression of the same set of genes. RNA was extracted using the Pure Link ${ }^{\mathrm{TM}}$ Plant RNA Reagent from Invitrogen following the manufacturer's protocol. RNA was treated with DNAse, visualized on an agarose gel (2\%) and its concentration measured using a Nanodrop spectrophotometer (ND-1000 Spectrophotometer, Thermo Scientific). RNA was converted to cDNA using similar amount of RNA across all the samples using the RevertAid ${ }^{\mathrm{TM}} \mathrm{H}$ Minus First Strand cDNA Synthesis Kit from Fermentas using a random hexamer primer according to manufacturer's protocol. Genomic contamination was assessed using the CYCLOIDEA 2 ( $L j C Y C 2$ ) intron in $L$. japonicus. The initial amount of cDNA was adjusted for each sample analyzed and an internal control of endogenous expression was assessed by the constitutive expression of L. japonicus Ubiquitin (LjUbi) using LjUbiF/R (Feng et al., 2006).

In this study we analyzed the expression of three genes from the anthocyanin biosynthetic pathway, dihydrofavonol 4-reductase (DFR), anthocyanin synthase (ANS) and O-methyltransferase (OMT). These genes were selected because they have been previously characterized in the model $L$. japonicus or other legumes, which facilitated primer design from conserved regions. Additional genes
Table 2

Sequences and annealing temperatures for the primers used to amplify the gene regions in the anthocyanin pathway.

\begin{tabular}{|c|c|c|c|}
\hline Gene region & Primer sequence $\left(5^{\prime}-3^{\prime}\right)$ & Size (bp) & $T_{\mathrm{m}}\left({ }^{\circ} \mathrm{C}\right)$ \\
\hline DFR1 & $\begin{array}{l}\text { DFR1F-GGATGAGACCTGCTGGGGTGACC } \\
\text { DFR1R-GATTCAGGGTGCTCGAAG }\end{array}$ & 315 & 53 \\
\hline DFR2 & $\begin{array}{l}\text { DFR2F-CGCCACTGTAAGAGACCCTG } \\
\text { DFR2R-AACATCGCTCCAGCAGCTC }\end{array}$ & 352 & 57 \\
\hline DFR3 & $\begin{array}{l}\text { DFR3F-CTCATGGAGGGCGGCTAC } \\
\text { DFR3R-GATCCTTGGAATTAAAGT }\end{array}$ & 214 & 55 \\
\hline DFR5 & $\begin{array}{l}\text { DFR5F-GAGAAGGTTGGTATTCAC } \\
\text { DFR5R-TGATGAGTGAGAGAGCAG }\end{array}$ & 281 & 55 \\
\hline ANS & $\begin{array}{l}\text { ANSF2-GCAGTGGGATACAATCTA } \\
\text { ANSR1-ATGGAGAGGTCACGCTTG }\end{array}$ & 433 & 55 \\
\hline OMT & $\begin{array}{l}\text { OMTF2-TCTGGAGACCAGTGTGTACC } \\
\text { OMTR2-TGAGTCTCTTGTGGTAGTTG }\end{array}$ & 432 & 56 \\
\hline LjUbiquitin & $\begin{array}{l}\text { LjUBiF-CCTTTTGAACAATTATGGTTTATTTGG } \\
\text { LjUbiR-GGCCACAACAAACGATACTACTTG }\end{array}$ & 75 & 55 \\
\hline
\end{tabular}

from the anthocyanin biosynthetic pathway, such as $F 3^{\prime} H, F L S$, and $\mathrm{F}^{\prime} 5^{\prime} \mathrm{H}$, deserve further analysis and were not included in this analysis as further characterization is still needed for the species we included.

Six DFR copies (DFR1, 2, 3, 4a/b, 5) have been reported in the L. japonicus genome and in this analysis we only included four, as the two DFR4 copies lack detectable functional activity in L. japonicus. New specific primers were designed for four of the DFR copies previously isolated in L. japonicus (Shimada et al., 2005). A conserved region of the ANS gene was amplified using a primer pair designed from a conserved region of the ANS from three species: L. corniculatus (AY028931) based on a partial cds (Paolocci et al., 2005), L. japonicus (chromosome 2, Miyakogusa.jp accession No. CM0304.350.nc) and Glycine max mRNA complete cds (EU334548). This gene has not been fully characterized in L. japonicus and in this analysis we amplified a conserved region, therefore we were not able to determine the number of copies of this gene in the species we analyzed. A specific primer pair was designed from a conserved region based on a previously published sequences from G. max (TIGR accession TC190220) (Kim et al., 2006), Medicago sativa CCOMT (U20736) and the best hit we found from the L. japonicus genome for this gene (chr. 4, CMO 227.500.nc+ phase). This particular copy of OMT was found to be specific for the conversion of quercetin to isorhamnetin in G. $\max$ (Kim et al., 2006). Primer sequences, expected size and annealing temperatures are reported in Table 2.

\section{Results}

\section{Evolution of flower color change in Macaronesian Lotus}

Within Macaronesian Lotus, we found that 21 (58\%) of the species sampled have the ability to modify flower color after anthesis. Flowers at anthesis (prechange) are always yellow or cream in all bee-pollinated species, and postchange flowers are either red ( 8 spp), purple (6 spp), brown (4 spp), orange (2spp) or pink (1 spp) (Fig. 2). The ability to change flower color after anthesis appears to be derived and it has evolved at least three times within this group. Notably, the bee-pollinated species that are most closely related to the putatively bird-pollinated Lotus have a flower color change to red after anthesis. Although the majority of the putatively bird-pollinated group is uniformly red or red/orange during development, the ability to modify flower color is still retained in $L$. pyranthus, which starts out orange and deepens to reddish-orange after anthesis (Fig. 2E). 


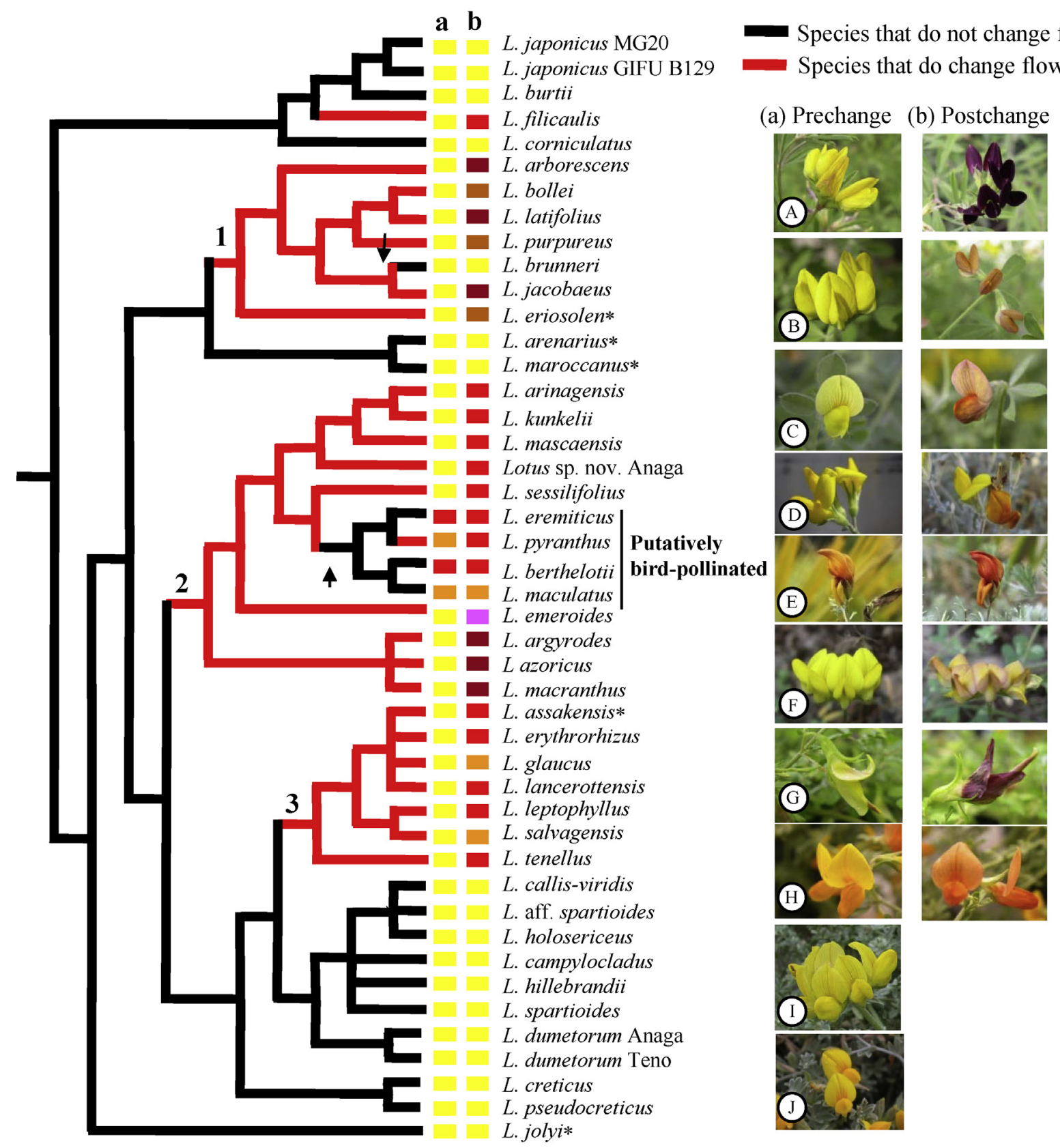

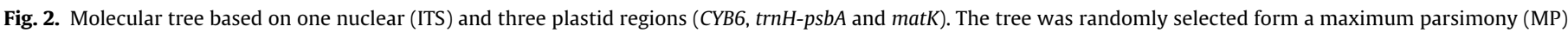

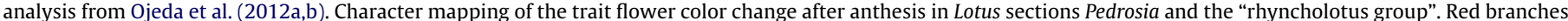

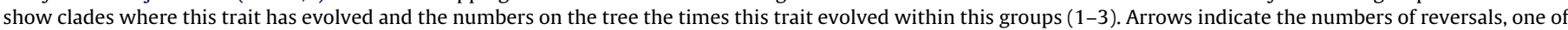

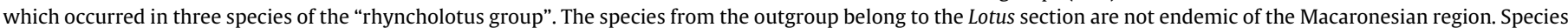

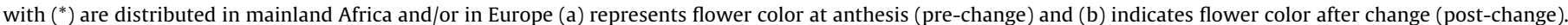

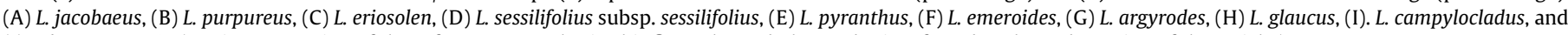
(J) L. lancerottensis. (For interpretation of the references to color in this figure legend, the reader is referred to the web version of the article.)

Photo credits: I. Ojeda and F. Oliva-Tejera.

Flower reflectance and color change perception

Our measurements included the three types of petals, dorsal, lateral and ventral, within each flower. We did not find differences in the reflectance measurements within the same petal of the same species. The results described below correspond to the dorsal petal only. Yellow flowers have at least three different major reflectance types (Table 3 ). The species typically have a reflectance peak above $500 \mathrm{~nm}$ (Fig. 3A-C). Seven species also have a UV peak in the reflectance spectrum. Prechange and postchange flowers within the same plant species have different reflectance spectrum, with the postchange reflectance peak shifted toward the red part of the spectrum and a slight reduction in the UV region (Table 3 , Fig. 3B and C). We found that flowers with deep purple colors tend to have a reflectance peak above $600 \mathrm{~nm}$, while red-orange flowers have a peak above $500 \mathrm{~nm}$. We also found that the presence of a UV 
Table 3

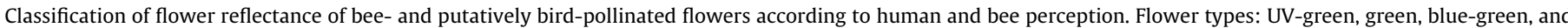

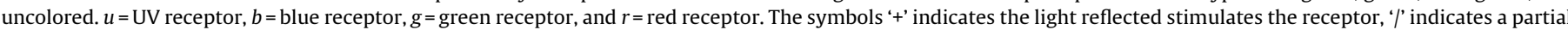
reduction while '-' indicates a lack of light reflected on the sensitivity range of each receptor. NA= not applicable.

\begin{tabular}{|c|c|c|c|c|c|c|}
\hline & \multicolumn{3}{|l|}{ Anthesis (prechange) } & \multicolumn{3}{|c|}{ After color change (postchange) } \\
\hline & Human color perception & Bee-flower color & Reflectance & Human color perception & Bee-flower color & Reflectance \\
\hline \multicolumn{7}{|c|}{ Bee-pollinated species } \\
\hline \multicolumn{7}{|c|}{ Without flower color change } \\
\hline L. campylocladus & Yellow & UV-green & $u+b-g+r+$ & NA & & NA \\
\hline L. callis-viridis & Yellow & UV-green & $u+b-g+r+$ & NA & & NA \\
\hline L. creticus & Yellow & UV-green & $u+b-g+r+$ & NA & & NA \\
\hline L. dumetorum & Yellow & Green & $u-b-g+r+$ & NA & & NA \\
\hline L. brunneri & Yellow & Green & $u-b-g+r+$ & NA & & NA \\
\hline \multicolumn{7}{|c|}{ With flower color change } \\
\hline L. purpureus & Yellow & UV-green & $u+b-g+r+$ & Brown & Green & $u-b-g+r+$ \\
\hline L. latifolius & Yellow & UV-green & $u+b-g+r+$ & Red & Green & $u-b-g+r+$ \\
\hline L. glaucus & Yellow & Blue-green & $u-b / g+r+$ & Orange & Green & $u-b-g / r+$ \\
\hline L. kunkelii & Yellow & Blue-green & $u-b / g+r+$ & Red & Green & $u-b-g / r+$ \\
\hline L. sessilifolius & Yellow & Green & $u-b-g+r+$ & Red & Green & $u-b-g / r+$ \\
\hline L. arinagensis & Yellow & Green & $u-b-g+r+$ & Red & Green & $u-b-g / r+$ \\
\hline L. mascaensis & Yellow & Green & $u-b-g+r+$ & Red & Green & $u-b-g / r+$ \\
\hline L. tenellus & Yellow & Green & $u-b-g+r+$ & Red & Green & $u-b-g / r+$ \\
\hline L. argyrodes & Yellow & Green & $u-b-g / r+$ & Purple & Uncolored & $u-b-g-r+$ \\
\hline L. jacobaeus & Yellow & Green & $u-b-g+r+$ & Purple & Uncolored & $u-b-g-r+$ \\
\hline \multicolumn{7}{|c|}{ Putatively bird-pollinated species } \\
\hline L. berthelotii & Red & Uncolored & $u-b-g-r+$ & NA & & NA \\
\hline L. eremiticus & Orange-brown & Uncolored & $u-b-g-r+$ & NA & & NA \\
\hline L. maculatus & Yellow-orange & Green & $u-b / g+r+$ & NA & & NA \\
\hline L. pyranthus & Orange & UV-green & $u+b-g+r+$ & Red & Green & $u-b-g+r+$ \\
\hline
\end{tabular}

peak is more common on those species with yellow flowers that lack postchange color (Table 3).

The putatively bird-pollinated species $L$. maculatus and $L$. pyranthus have reflectance in the action spectra of the bird green and red visual receptors. Lotus pyranthus has an additional UV peak in early anthesis orange flowers (older flowers turn redder but still maintain the UV peak). The other two putatively bird-pollinated species ( $L$. berthelotii and $L$. eremiticus) have a reflectance peak restricted to the red receptor (above $600 \mathrm{~nm}$ ) and are thus likely to be poorly distinguished from the green foliage background by bees (Fig. 3D).

\section{Petal pigment composition in Lotus}

The flavonoids identified suggest that two branches of the anthocyanin pathway, the cyanidin and delphinidin branches are active at anthesis in flowers of the Macaronesian Lotus (section Pedrosia). We did not find any anthocyanidin derivatives of the pelargonidin branch (with a dihydrokaempferol precursor) in any of the species analyzed. We conclude that the pelargonidin branch of the anthocyanin biosynthetic pathway is not active in flowers of any of the sections of Lotus tested. Additionally, we identified three

Table 4

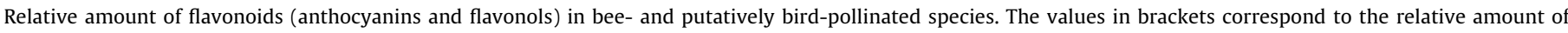
pigment after color change.

\begin{tabular}{|c|c|c|c|c|c|c|c|c|}
\hline & \multicolumn{5}{|l|}{ Anthocyanins } & \multicolumn{3}{|l|}{ Flavonols } \\
\hline & Cyanidin & Peonidin & Delphinidin & Malvidin & Petunidin & Quercetin & Kaempferol & Isorhamnetin \\
\hline \multicolumn{9}{|c|}{ Bee-pollinated species } \\
\hline \multicolumn{9}{|c|}{ Without flower color change } \\
\hline L. spartioides & 1.1 & 0 & 2.55 & 0 & 0 & 7.38 & 2.08 & 9.45 \\
\hline L. callis-viridis & 0.04 & 0 & 0.04 & 0 & 0 & 2.2 & 0.84 & 1.97 \\
\hline L. dumetorum & 0.08 & 0 & 0 & 0 & 0 & 3.69 & 1.67 & 8.08 \\
\hline L. brunneri & 0 & 0 & 0 & 0 & 0 & 3.95 & 2.43 & 1.49 \\
\hline L. campylocladus & 0.5 & 0 & 0.48 & 0 & 0 & 3.34 & 2.01 & 5.69 \\
\hline \multicolumn{9}{|c|}{ With flower color change } \\
\hline L. sessilifolius (1) & $2.14(6.07)$ & $0.02(1.80)$ & $1.72(9.31)$ & $0(2.90)$ & $0(0.87)$ & $2.47(3.50)$ & $0.71(0.87)$ & $6.21(14.40)$ \\
\hline L. sessilifolius (2) & $3.27(6.28)$ & $0.02(0.24)$ & $4.1(10.0)$ & $0.03(1.32)$ & $0(1.29)$ & $3.93(7.02)$ & $1.64(1.56)$ & $7.84(16.00)$ \\
\hline L. mascaensis & $1.83(8.10)$ & $0(0.90)$ & $1.83(10.26)$ & $0(3.99)$ & $0(2.53)$ & $4.21(4.36)$ & $2.23(2.55)$ & $15.48(15.68)$ \\
\hline L. argyrodes & $0(7.97)$ & $0(5.84)$ & $0(7.06)$ & $0(39.2)$ & $0(6.98)$ & $1.07(1.51)$ & $2.20(24.35)$ & $3.70(15.70)$ \\
\hline L. jacobaeus & $0(6.3)$ & $0(18.64)$ & $0(26.30)$ & $0(42.5)$ & $0(40.6)$ & $2.97(15.70)$ & $2.43(5.11)$ & $4.37(5.17)$ \\
\hline L. glaucus & $0(9.5)$ & $0(2.69)$ & $0(15.92)$ & $0(1.97)$ & $0(6.58)$ & $12.21(23.12)$ & $1.90(4.53)$ & $6.23(15.94)$ \\
\hline L. arinagensis & $0(4.5)$ & $0(0.24)$ & $0(11.03)$ & $0(1.62)$ & $0(3.99)$ & $6.24(14.32)$ & $0.70(4.45)$ & $2.39(8.25)$ \\
\hline L. emeroides & $0(4.0)$ & $0(1.48)$ & $0(3.7)$ & $0(3.12)$ & $0(3.97)$ & $7.79(8.78)$ & $1.49(1.16)$ & $5.20(33.90)$ \\
\hline L. tenellus & $0.82(5.35)$ & $0(0.81)$ & $0.17(8.96)$ & $0(1.75)$ & $0(3.73)$ & $13.78(11.35)$ & $1.67(0.87)$ & $6.23(2.92)$ \\
\hline \multicolumn{9}{|c|}{ Putatively bird-pollinated species } \\
\hline L. berthelotii (1) & 22.7 & 0.78 & 6.55 & 0.16 & 0.98 & 14.63 & 1.93 & 0.70 \\
\hline L. berthelotii (2) & 33.0 & 3.5 & 9.7 & 0.88 & 0 & 18.11 & 1.8 & 0 \\
\hline L. maculatus & 9.6 & 0.203 & 8.6 & 0.22 & 0 & 24.49 & 0.49 & 0 \\
\hline L. eremiticus & 9.15 & 0.58 & 8.90 & 0.92 & 0.45 & 5.24 & 0.14 & 2.65 \\
\hline L. pyranthus & $2.82(23.4)$ & $0(0.18)$ & $5.1(28.1)$ & $0(0)$ & $0(0.72)$ & $7.76(12.40)$ & $0.34(0.62)$ & $0.13(0.32)$ \\
\hline
\end{tabular}



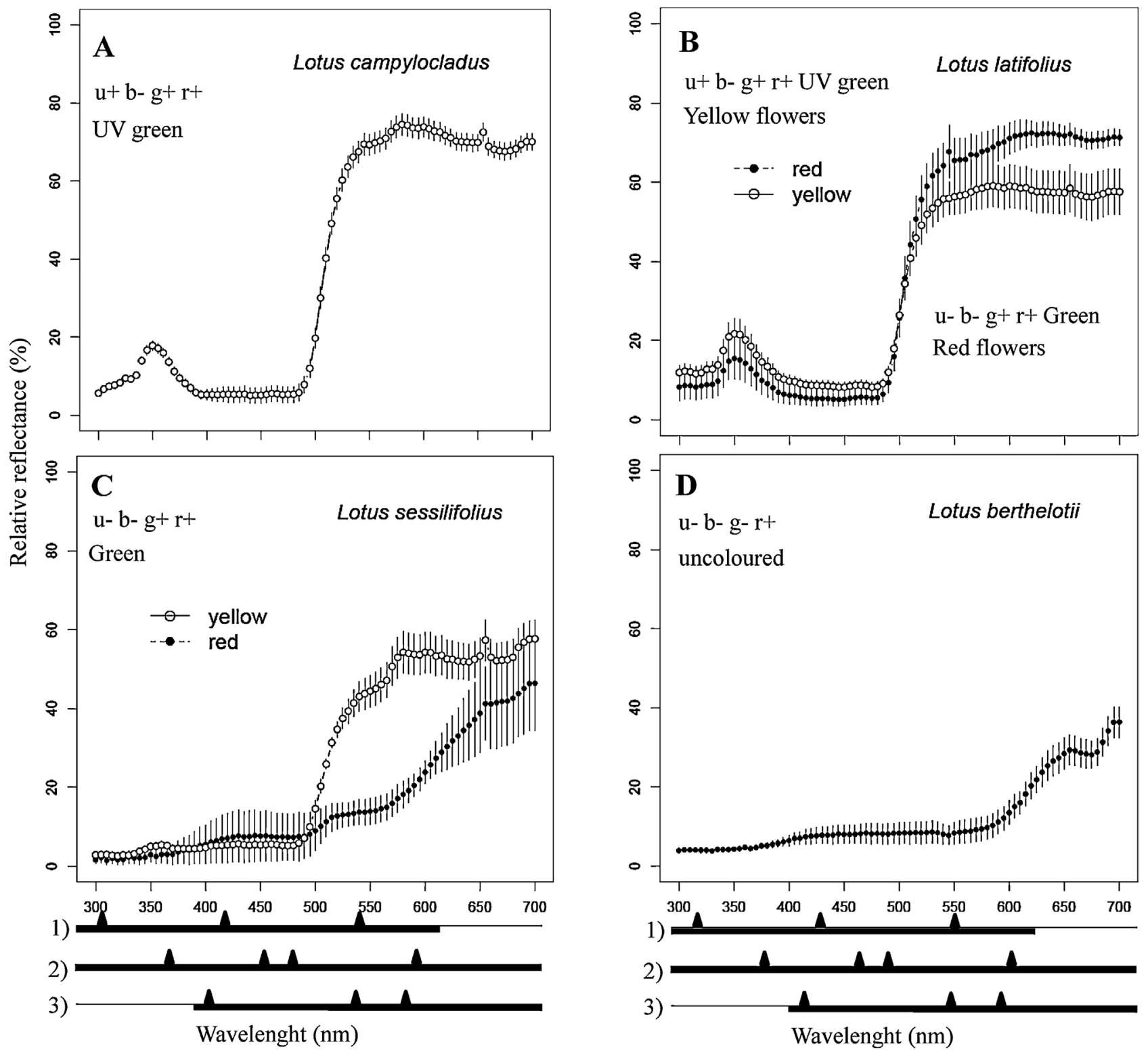

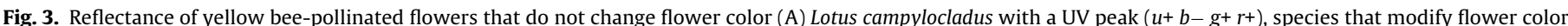

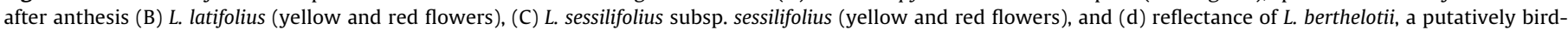

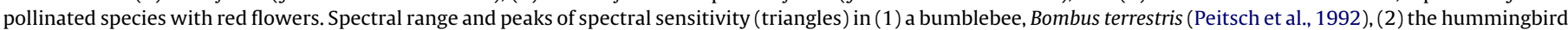

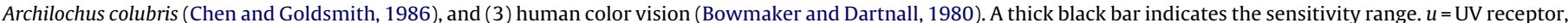

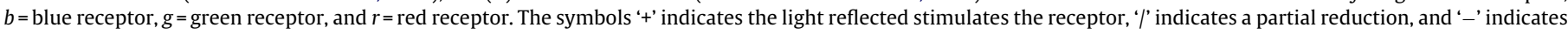

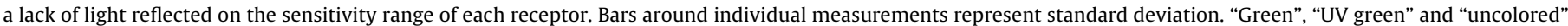
correspond to bee color perception. (For interpretation of the references to color in this figure legend, the reader is referred to the web version of the article.)

different flavonols (or their derivatives): kaempferol, quercetin, and isorhamnetin. These were present (in various amounts) in all species we analyzed.

Pigments in yellow flowers without post-anthesis flower color modification

Yellow flowers of these species (5 spp analyzed) contain a mixture of flavonols (mainly isorhamnetin) and traces of anthocyanin pigments. We found delphinidin and cyanidin in three out of five species analyzed, which suggests that these branches are active even in species that do not change flower color after anthesis. However, the amount of anthocyanin pigment in these five species is minimal compared to the flavonols, which are present in large amounts (Table 4). Additionally, the fact that these pigments were found in non-methylated forms indicates a lack of pathway progression down these biosynthetic branches to methylated derivatives (Fig. 4A).

Pigments in yellow-flowered species that modify flower color after anthesis

Yellow flowers (prechange) have a composition of flavonols (mainly isorhamnetin) similar to that in species that do not modify flower color, but the relative amount of delphinidin and cyanidin is greater (Fig. 4B). In older flowers (postchange), 

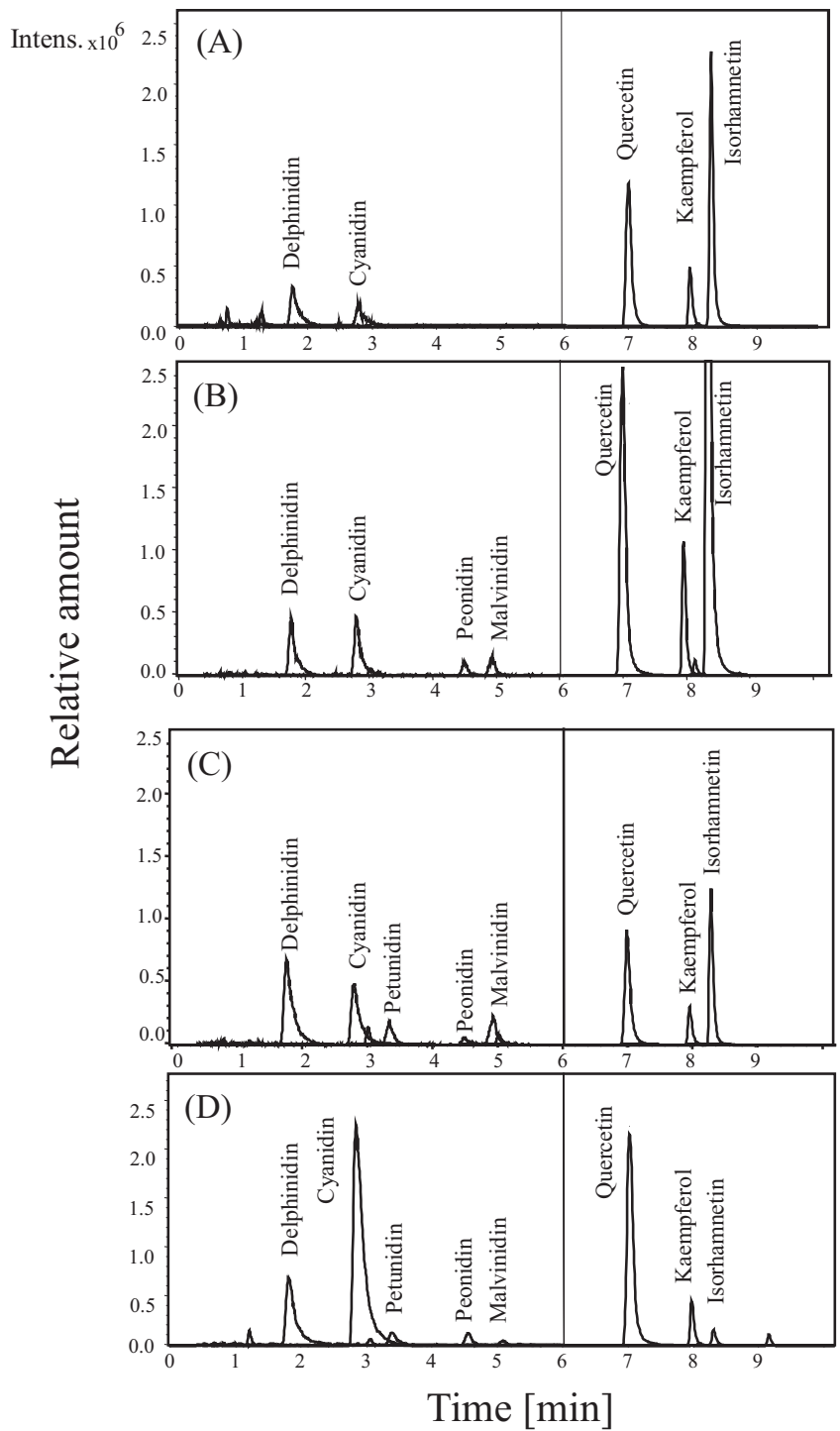

Fig. 4. Liquid chromatography-mass spectrometry (LC-MS) of bee-pollinated flowers (A) Lotus spartioides, a species with yellow flowers that do not modify flower color after anthesis, (B) prechange yellow flowers of L. sessilifolius subsp. sessilifolius, (C) postchange red flowers of $L$. sessilifolius, and (D) a putatively bird-pollinated species, L. berthelotii, with red flowers. The area under the peak for each pigment identified was used to estimate the relative amount of each pigment. (For interpretation of the references to color in this figure legend, the reader is referred to the web version of the article.)

further anthocyanidin pathway progression occurs. In addition to delphinidin and cyanidin, we found methylated derivatives, i.e. peonidin, malvidin and petunidin, in these species. The pigment composition of these postchange flowers varied consistently with the color of each species. Purple and pink flowers tend to have more derivatives of the delphinidin branch while red and orange flowers have more derivatives of the cyanidin branch.

The closest relatives of the putatively bird-pollinated flowers ( $L$. sessilifolius, $L$. arinagensis and L. mascaensis) have a color change to red flowers in late anthesis. In these species, all five anthocyanins detected in the putatively bird-pollinated species (cyanidin, delphinidin, malvidin, peonidin, petunidin) were already present in the yellow flowers, but their amounts increased substantially during flower color modification (postchange flowers) (Fig. 4B and C) (Table 4).

\section{Pigments in red/orange, putatively bird-pollinated species}

This group of species (4 spp.) contains abundant cyanidin derivatives, and the main flavonol is quercetin (rather than isorhamnetin) (Fig. 4D, Table 4). But, the same branches of the anthocyanin pathway are active, and flavonols still contribute to pigment composition in these species. However, the main flux of flavonoid production is toward anthocyanins, particularly the cyanidin and delphinidin branches of the anthocyanin pathway. All flavonol production is reduced, but this is especially marked in the case of isorhamnetin, a derivative of quercetin. Thus, the transition from bee- to the putatively bird-pollinated species in this group appears to involve a quantitative re-direction of pigment production from flavonols to anthocyanins (Figs. 4 and 5), similar to but greater than the re-direction during post-anthesis change in bee-pollinated species.

\section{Gene expression comparisons during flower color modification}

Five of the structural enzymes we examined are expressed at late developmental stages at least in one species. We did not find any expression of DFR3 (Fig. 6) in any of the species tested. Two genes, ANS and DFR1, are expressed uniformly in all species. DFR2 is not expressed in the putatively bird-pollinated species but was expressed in all other species. DFR5 is not expressed in species of section Lotus (L. japonicus and L. filicaulis) but is strongly expressed in all other species sampled (section Pedrosia + the "rhyncholotus group"). OMT has a reduced expression in late developmental stages in the putatively bird-pollinated species (lateral and ventral petals), but it is expressed at earlier developmental stages in the putatively bird-pollinated species tested, L. berthelotii (Fig. 6 and Fig. S1)

Supplementary material related to this article found, in the online version, at http://dx.doi.org/10.1016/j.plantsci.2004.08.011.

\section{Discussion}

Flower color change as a possible exaptation in the evolution of ornithophily in Lotus

From observations of close relatives (Figs. 1H and 2D), the ancestor of the putatively Canarian bird-pollinated species likely had red flowers in late anthesis, which might have been an exaptation (Gould and Vrba, 1982) facilitating the evolution of this pollination syndrome in these islands. The entomophilous ancestors already had the capacity to produce the pigments (cyanidin and delphinidin derivatives) observed in these putatively bird-pollinated species. Thus, the evolution of red/orange colors might only have required a heterochronic shift from late (facultative) to early (constitutive) anthocyanin pigmentation.

Our character mapping analysis suggests that the ability to modify flower color after anthesis has independently evolved three times within the Macaronesian Lotus group (Fig. 2). However, the flower features associated with bird pollination evolved relatively recently in only one of these clades (Ojeda et al., 2012a,b). Thus, although flower color change may have been a prerequisite that facilitated the evolution of this flower morphology, additional conditions may have been required for the evolution of this pollination syndrome in only this clade. Such conditions may be ecological, as for instance the availability of new habitats in Tenerife and La Palma islands due to volcanic activity (Ojeda et al., 2012b).

Flower color change is not a unique feature of Lotus section Pedrosia, as it has been reported in at least in $20 \%$ of angiosperm families. It has previously been reported in at least 25 genera within 


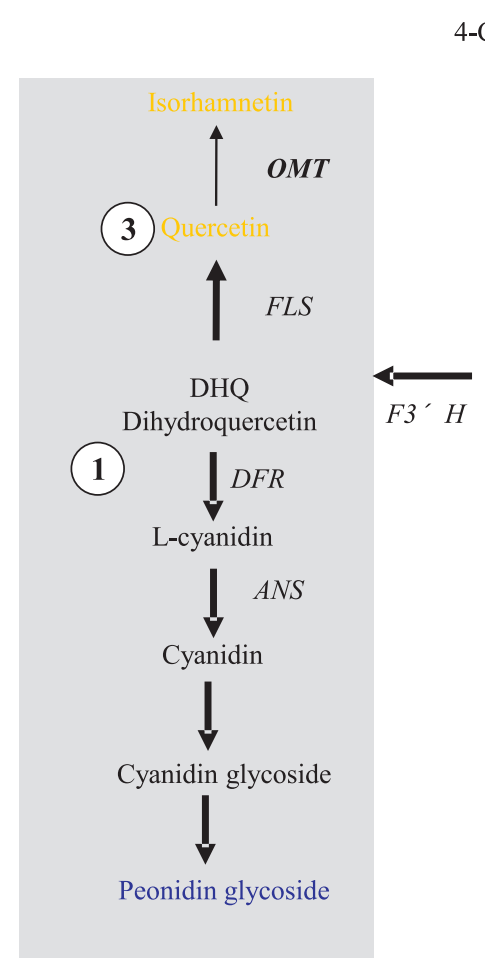

4-Coumaryl-CoA + Malonyl-Coa

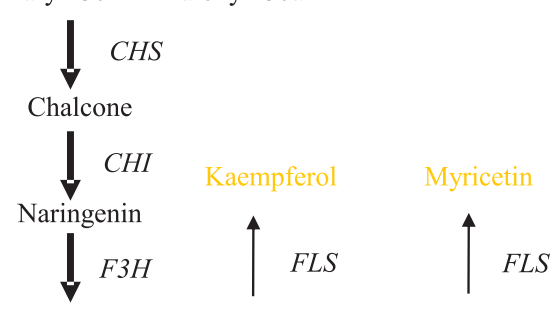

FLAVONOLS

DHM

DIHYDRO-FLAVONOLS

Dihydromyricetin
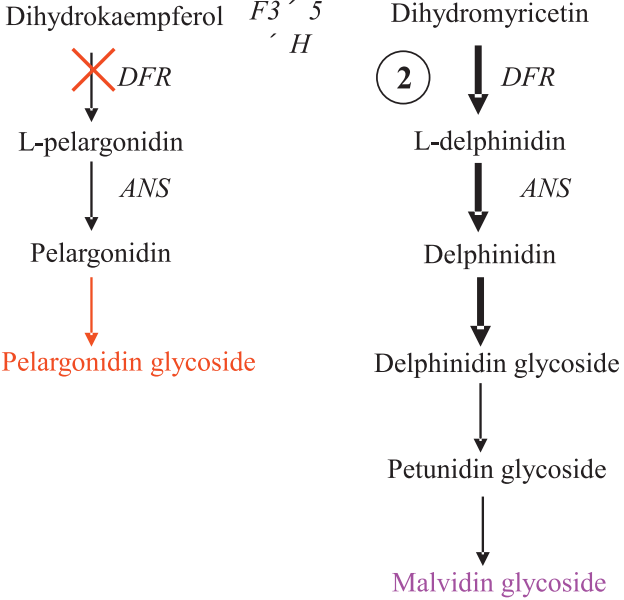

LEUCOANTHO-CYANIDINS

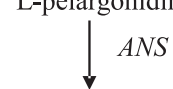

ANS

Pelargonidin

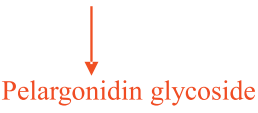

ANTHOCYANIDINS

ANTHOCYANINS

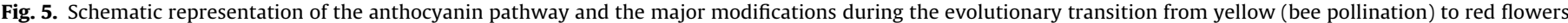

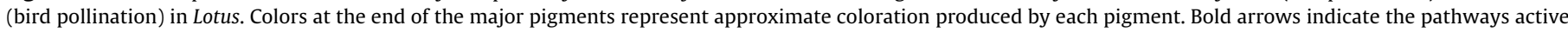

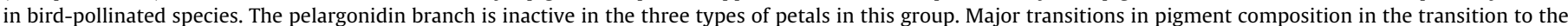

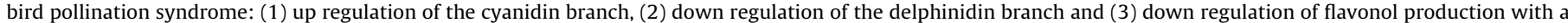

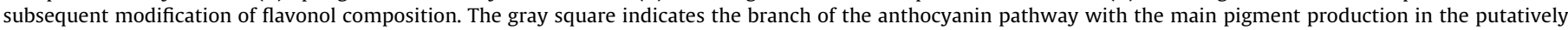

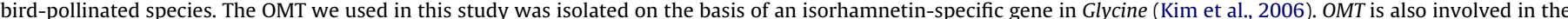

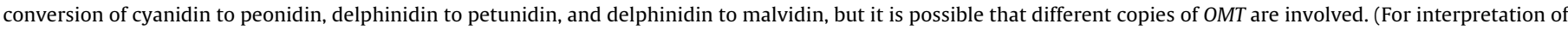
the references to color in this figure legend, the reader is referred to the web version of the article.)

legumes (Weiss, 1995), including Lupinus (Gori, 1983), Caesalpinea (Cruden and Hermann-Parker, 1979), Syrmatium (Jones and Cruzan, 1982, 1999), Desmodium (Willmer et al., 2009) and in another four species within Lotus (Weiss, 1995). It might be of interest to examine whether the evolution of bird pollination in other genera within Leguminosae, and in other families, may have been facilitated by this characteristic.

\section{Color change in flowers as a bee deterrence mechanism}

What is the fitness advantage for a particular species to modify flower color after anthesis? Although we have no empirical data from these insular Lotus, there is substantial empirical evidence that an increase in insect visitation rate, fruit set and pollinator foraging efficiency accompanies late-anthesis color change in many species (Jones and Cruzan, 1982; Oberrath and Böhning-Gaese, 1999; Willmer et al., 2009). Postchange late-anthesis flowers may still contribute to the overall floral display and attract pollinators at long distance; but at short range, prechange unpollinated flowers (with reward) can be distinguished from postchange, probably pollinated flowers (without reward). Pollinator activity is therefore directed efficiently toward those flowers less likely to have been pollinated. Additional floral changes (such as flower orientation, size, shape and odor production) may act in conjunction with color modifications (Eisikowitch and Rotem, 1987; Raguso, 2004; Willmer et al., 2009), and it is likely that all these floral alterations after anthesis are an integrated system to increase foraging efficiency at least in some plant species (Raguso, 2008).

\section{Color change in Lotus flowers is likely to be perceived by bees}

Our petal reflectance data in Lotus (Table 3) suggests that floral color change in Macaronesian Lotus within the same species causes differential reflectance that will stimulate different receptors in the pollinators. The different floral stages are thus likely to be perceived differently by the insect visual system. Most hymenopteran species analyzed to date have trichromatic color vision with three types of spectral sensitivity, for example for Apis mellifera: UV-A (S-receptor; $\lambda_{\max }=340 \mathrm{~nm}$ ), blue (M-receptor; $\lambda_{\max }=430 \mathrm{~nm}$ ) and green (L-receptor; $\lambda_{\max }=535 \mathrm{~nm}$ ) receptors (Menzel and Backhaus, 1991). These insects do not react to reflectance peaks above $585 \mathrm{~nm}$ (Chittka et al., 1994; Briscoe and Chittka, 2001), and red flowers with peaks above 585 will not stand out from the green foliage (but see Schikora et al., 2002; Skorupski et al., 2007). These postchange floral color modifications involve a shift away from the green wavelength detected by the L-receptor of insects (Fig. 3B and C). Furthermore, in those species with prechange UV reflection there is a reduction of UV (S-receptor) in postchange flowers (MartinezHarms et al., 2010). The presence of a UV peak in some species indicates that Lotus flowers that look the same to the human eye (yellow) (Bowmaker and Dartnall, 1980) are of at least three types to bees (Table 3 ). These three types are: UV- 


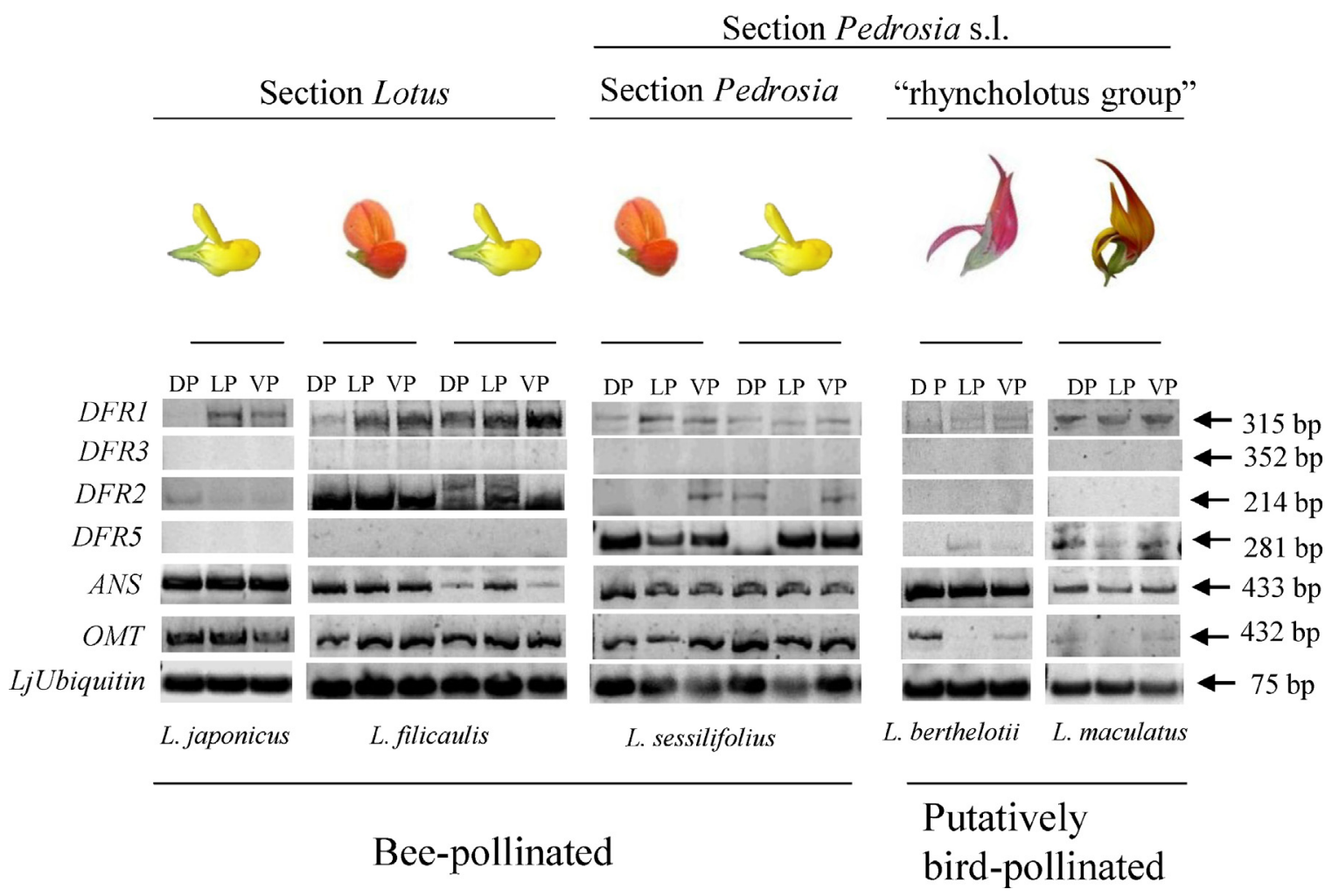

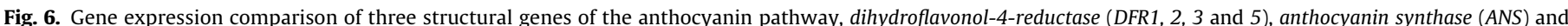

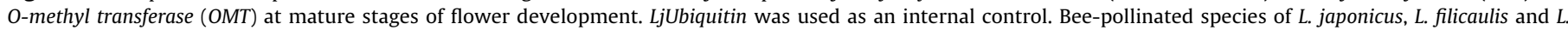

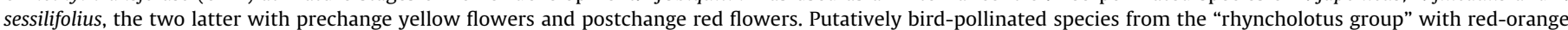

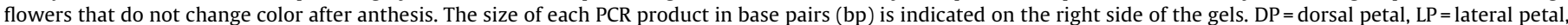

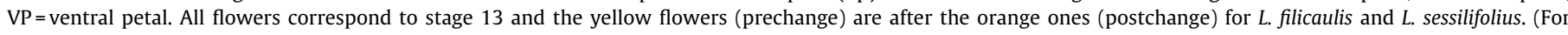
interpretation of the references to color in this figure legend, the reader is referred to the web version of the article.)

green, green and blue-green. Two of these types, UV-green and blue-green, have not been reported previously in Lotus (Floral Reflectance Database, FreD: http://reflectance.co.uk/new/) (Arnold et al., 2010).

Red/orange color in the putatively bird-pollinated Lotus may have evolved as an anti-bee and pro-bird strategy

In general, red bird-pollinated flowers tend to have reflectance peaks above $585 \mathrm{~nm}$, and do not reflect at any wavelength detectable to most bees (Chittka and Waser, 1997; Briscoe and Chittka, 2001; Martinez-Harms et al., 2010). Thus, red birdpollinated flowers are more difficult for insects to distinguish from the plant foliage (as background) which reflects in several wavelengths visible to bees (Chittka and Waser, 1997), and they will not stand out. The same is true for the putatively bird-pollinated Lotus. A previous study has reported the reflectance of $L$. berthelotii (Ollerton et al., 2009), which has the typical reflectance spectrum of a bird-pollinated flower (Chittka et al., 1994; Altshuler, 2003; Martinez-Harms et al., 2010). Our results indicate that only two out of the four putatively bird-pollinated species ( $L$. berthelotii and L. eremiticus) have this pattern, which lacks reflectance in the UV and blue, and has a peak in the red range above $585 \mathrm{~nm}$ (Fig. 3D). The other two putatively bird-pollinated species (L. maculatus and L. pyranthus) do have some reflectance in wavelengths perceived by the green visual receptor, and are similar in that regard to the bee-pollinated yellow flowers after late-anthesis color change to red (Table 3). This provides a link between the two flower types, which may be significant in understanding the evolution of bird pollination in the group.
Birds have a more sophisticated visual system than hymenopterans. They have four photoreceptor sensitivities (VS, S, M and L) and cone oil droplets that enhance their vision (Chen and Goldsmith, 1986; Hart et al., 2000). It has been proposed before (Raven, 1972) that red coloration evolved in some plant groups as an adaptation to exclude bees. Birds seem to lack an innate preference for red colors (Grant and Grant, 1968; Lunau and Maier, 1995), but several experiments have shown that they quickly associate floral reward with particular colors (Grant, 1966; Gottsberger, 1971). Our reflectance analyses therefore suggest that red/orange-pigmented flowers in the four rhyncholotus species might have evolved to deter bees (anti-bee) as much as to be an advertisement to birds (pro-bird). They have less UV reflectance than the bee-pollinated Lotus species, and similar observation have been made on hummingbird flowers in the neotropics (Lunau et al., 2011). These Lotus flowers also have other traits that may function more as anti-bee features than pro-bird features. The putatively bird-pollinated species have dilute nectar composed mainly of hexose sugars (Dupont et al., 2004), which is more difficult to evaporate into honey and it is less efficient from an energetic point of view. They also lack papillose conical cells on the petal epidermal surface exposed to pollinators (Ojeda et al., 2012a,b), which make the surface more difficult to grip (Whitney et al., 2009, 2011).

The changing balance of anthocyanin and flavonol pigment composition in bee and bird pollination in Lotus

In many systems, transitions in pollination syndrome have mainly involved the activation/inactivation of particular branches 
of the anthocyanin biosynthetic pathway (Scogin and Freeman, 1987; Zufall and Rausher, 2003; Rausher, 2008; Streisfeld and Rausher, 2009; Smith and Rausher, 2011). Unlike other plant groups analyzed before, the transition in Lotus from bee- (yellow/cream) to putatively bird-(red/orange) pollinated flowers does not seem to involve novel inactivation or activation of branches of the anthocyanin pathway. Rather, this transition involved the increased production of derivatives of the dihydroquercetin precursor in the putatively bird-pollinated species that were already present in the closest relative bee-pollinated species, partly at the expense of flavonol production.

Flavonoid biosynthesis in Lotus is through dihydroflavonols, such as dihydroquercetin (DHQ) which is a precursor of both flavonols (quercetin and isorhamnetin) and anthocyanins (cyanidin), depending of the enzyme systems active (Grotewold, 2006; Tanaka et al., 2008). Therefore, at the biochemical level, the transition in flower color appears to involve the re-direction of pathway flux toward the cyanidin branch, which is the main anthocyanin observed in the putatively bird-pollinated flowers (Fig. 4D). On the other hand, the flavonols kaempferol and isorhamnetin are greatly reduced in bird-pollinated flowers, and have a relatively minor contribution to the overall flavonoid composition in comparison to bee-pollinated flowers (Fig. 4). It may be that this redirection of flux results from a small but significant shift in the balance of competition for substrates by enzymes in these branches. Flower color change both developmental (prechange and postchange), and evolutionary (pollinator shifts) therefore appears to result from modified flux into already active branches in the anthocyanin pathway; pigment production is re-directed toward the cyanidin and delphinidin branches instead of toward flavonols, which decrease.

Our gene expression data from mature flowers in the two species groups also indicates that the genes required, ANS, DFR and $O M T$, for the production of these pigments are active in both bee and putatively bird-pollinated species (Fig. 6). Gene expression analyses of earlier developmental stages in L. japonicus and L. berthelotii also confirm that these genes in the anthocyanin metabolic pathway are active in early flower developmental stages in both species (Fig. S1). Our results confirm that one copy of DFR (DFR3) is not expressed in floral tissue of any species, and is likely to be expressed only vegetatively as previously reported (Shimada et al., 2005). Our results also indicate that the pelargonidin branch is not active in the petals of the species sampled, as no anthocyanidin derivatives of the dihydrokaempferol were observed. These results are consistent with a previous report, which indicates that the pelargonidin branch is not active in stems of $L$. japonicus (Shimada et al., 2005). Additional genes not explored in this study, such as flavonol synthase (FLS), will be of particular interest, as well as to examine definitely whether ANS and OMT are single or multi-copy in the various species of Lotus, and to further characterize their particular roles in the color modifications of this group.

\section{Concluding remarks}

Our results show that the four putatively bird-pollinated Macaronesian Lotus evolved within a group of entomophilous species which already have the capacity to produce the anthocyanin cyanidin and delphinidin derivatives. The shift in flower color between the two pollination syndromes therefore only involved a redirection of pigment production toward anthocyanin, rather the activation or inactivation of new branches within the anthocyanidin pathway.

Pigment changes after flower anthesis evolved independently at least three times in Macaronesian Lotus, probably as an aid to deter bees from visiting already pollinated flowers, and so increase pollinator foraging efficiency in the bee-pollinated species. Consistent with this, our spectral reflectance data indicates that modifications in pigment composition between prechange and postchange flowers in bee-pollinated species are likely to be perceived differently by the insect visual system. Later, this trait appears to have been co-opted and amplified in the four birdpollinated species to produce the characteristic red/orange flowers of this group. Post-anthesis color change may therefore be a preadaptation (exaptation), facilitating the shift to bird pollination by providing the same function (deterrence of bee visitation) in a different context.

\section{Funding}

Funding for this work was provided by Consejo Nacional de Ciencia y Tecnología (CONACyT) from Mexico to D.O., by a grant from the NSERC Discovery Grant program (Canada) to Q.C. and by the project No. RF2006-00030 from the Instituto Nacional de Investigación y Tecnología Agraria y Alimentaria to A.S.G., and by Ministerio de Ciencia e Innovación from Spain by the project DE2009-0091 and a Ramón y Cajal postdoctoral grant (RYC-200700620) to A.V.

\section{Acknowledgments}

The authors thank the staff of the University of British Columbia (UBC) Botanical Garden, Instituto Canario de Investigaciones Agrarias (ICIA- Tenerife) and Jardín Botánico Canario "Viera y Clavijo" from Gran Canaria. Seeds of Lotus arenarius and L. eriosolen were kindly provided by USDA, ARS National Genetic Resources Program. Special thanks to Lina Madilao from UBC for her help with LC-MS analysis.

\section{References}

Allan, G.J., Francisco-Ortega, J., Santos-Guerra, A., Boerner, E., Zimmer, E.A., 2004. Molecular phylogenetic evidence for the geographic origin and classification of Canary Island Lotus (Fabaceae: Loteae). Mol. Phylogenet. Evol. 32, 123-138.

Altshuler, D.L., 2003. Flower color, hummingbird pollination, and habitat irradiance in four neotropical forests. Biotropica 35, 344-355.

Arnold, S.E.J., Faruq, S., Savolainen, V., McOwan, P.W., Chittka, L., 2010. FReD: the floral reflectance database - a web portal for analyses of flower colour. PLoS ONE 5 (12), e14287.

Bowmaker, J.K., Dartnall, H.J.A., 1980. Visual pigments of rods and cones in a human retina. J. Physiol. (Lond.) 298, 501-511.

Bramwell, D., Bramwell, Z.I., 2001. Flores silvestres de las islas Canarias. Editorial Rueda, Madrid.

Briscoe, A.D., Chittka, L., 2001. The evolution of colour vision in insects. Annu. Rev. Entomol. 46, 471-510.

Brochman, C., Rustan, O.H., Lobin, W., Kilian, N., 1997. The endemic vascular plant of the Cape Verde Islands, W. Africa. Sommerfeltia 24, 213-228.

Chen, D.M., Goldsmith, T.H., 1986. Four spectral classes of cone in the retina of birds. J. Comp. Physiol. A 159 (473), 479.

Chittka, L., Shmida, A., Troje, N., Menzel, R., 1994. Ultraviolet as a component of flower reflections and the color perception of Hymenoptera. Vision Res. 34, 1489-1508.

Chittka, L., Waser, N.M., 1997. Why red flowers are not invisible to bees. Israel J. Bot. 45, 169-183.

Cronk, C., Ojeda, I., 2008. Bird-pollinated flowers in an evolutionary and molecular context. J. Exp. Bot. 59, 715-727.

Cruden, R.W., Hermann-Parker, S.M., 1979. Butterfly pollination of Caesalpinia pulcherrima, with observation of a psychophilous syndrome. J. Ecol. 67, 155-168.

Degtjareva, G.V., Kramina, T.E., Sokoloff, D.D., et al., 2006. Phylogeny of the genus Lotus (Leguminosae, Loteae): evidence from nrITS sequences and morphology. Can. J. Bot. 84, 813-830.

Dupont, Y.L., Hansen, D.M., Rasmussen, J.T., Olesen, J.M., 2004. Evolutionary changes in nectar sugar composition associated with switches between bird and insect pollination: the Canarian bird-flower element revisited. Funct. Ecol. $18,670-676$.

Eisikowitch, D., Rotem, R., 1987. Flower orientation and color change in Quisqualis indica and their possible role in pollinator partitioning. Bot. Gazette 148, $175-179$.

Feng, X., Zhao, Z., Tian, Z., et al., 2006. Control of petal shape and flower zygomorphy in Lotus japonicus. Proc. Natl. Acad. Sci. U.S.A. 103, 4970-4975. 
Francisco-Ortega, J., Fuertes-Aguilar, J., Kim, S.C., et al., 2002. Phylogeny of the Macaronesian endemic Crambe section Dendrocrambe (Brassicaceae) based on internal transcribed spacer sequences of nuclear ribosomal DNA. Am. J. Bot. 89, 1984-1990.

García-Maroto, F., Mañas-Fernández, A., Garrido-Cárdenas, J.A., et al., 2009. Delta6desaturase sequence evidence for explosive Pliocene radiations within the adaptive radiation of Macaronesian Echium (Boraginaceae). Mol. Phylogenet. Evol. 52, 563-574.

Gori, D.F., 1983. Floral color change in Lupinus argenteus (Fabaceae): why should plants advertise the location of unrewarding flowers to pollinators? Evolution $43,870-881$.

Gottsberger, G., 1971. Colour changes of petals in Malvaviscus arboreus flowers. Acta Bot. Neerland. 20, 381-388.

Gould, S.J., Vrba, E.S., 1982. Exaptation - a missing term in the science of form. Paleobiology 8, 4-15.

Grant, K.A., 1966. A hypothesis concerning the prevalence of red coloration in California hummingbird flowers. Am. Nat. 100, 85-97.

Grant, K.A., Grant V, 1968. Hummingbirds and Their Flowers. Columbia University Press, New York and London.

Grotewold, E., 2006. The genetics and biochemistry of floral pigments. Annu. Rev. Plant Biol. 57, 61-80.

Guzmán, B., Vargas, P., 2005. Systematics, character evolution, and biogeography of Cistus L, (Cistaceae) based on ITS, trnL-trnF, and matK sequences. Mol. Phylogenet. Evol. 37, 644-660.

Hart, N.S., Partridge, J.C., Cuthill, I.C., Bennett, A.T.D., 2000. Visual pigments, oil droplets, ocular media and cone photoreceptor distribution in two species of passerine bird: the blue tit (Parus caeruleus L.) and the blackbird (Turdus merula L.). J. Comp. Physiol. A 4, 375-387.

Hohmann, H., La Roche, F., Ortega, G., Barquín, J., 1993. Bienen, Wespen und Ameisen der Kanarischen Inseln (Insecta: Hymenoptera: Aculeata). I-II. Veröffentlichungen aus dem Übersee-Museum Bremen. Naturwissenschaften 12, 14-712.

Jardim, R., Francisco, D., 2000. Flora endemica da Madeira. Muchia Publication, Madeira.

Jones, C.E., Cruzan, M., 1982. Floral color changes in deerweed (Lotus scopiurus): possible function. Crossosoma 8, 1-6.

Jones, C.E., Cruzan, M.B., 1999. Floral morphological changes and reproductive success in deer weed (Lotus scopiurus, Fabaceae). Am. J. Bot. 86, 273-277.

Jorgensen, T.H., Olesen, J.M., 2001. Adaptive radiation of island plants: evidence from Aeonium (Crassulaceae) of the Canary Islands. Perspect. Plant Ecol. Evol. Systemat. 4, 29-42.

Kim, S.C., Crawford, D.J., Francisco-Ortega, J., Santos-Guerra, A., 1996. A common origin for woody Sonchus and five related genera in the Macaronesian islands: molecular evidence for extensive radiation. Proc. Natl. Acad. Sci. U.S.A. 93, 7743-7748.

Kim, B.G., Lee, H.J., Park, Y., Lim, Y., Ahn, H., 2006. Characterization of an O-methyl transferase from soybean. Plant Physiol. Biochem. 44, 236-241.

Lunau, K., Maier, E.J., 1995. Innate colour preferences of flower visitors. J. Comp. Physiol. A 177, 1-19.

Lunau, K., Papiorek, S., Eltz, T., Sazima, M., 2011. Avoidance of achromatic colours by bees provides a private niche for hummingbirds. J. Exp. Biol. 214, 1607-1612.

Maddison, D.R., Maddison, W.P., 2005. MacClade 4: Analysis of Phylogeny and Characte Revolution, version 4.08a. http://macclade.org

Maddison, W.P., Maddison, D.R., 2011. Mesquite: A Modular System for Evolutionary Analysis, version 2.75. http://mesquiteproject.org

Mader, U., Podlech, D., 1989. Revision der marokkanischen Arten von Lotus L. subgenus Pedrosia ( $R$, Lowe) Brand (Leguminosae). Mitteilungen (aus) der Botanischen Staatssammlung München 28, 513-567.

Martinez-Harms, J., Palacios, A.G., Márquez, N., et al., 2010. Can red flowers be conspicuous to bees? Bombus dahlbomii and South American temperate forest flowers as a case in point. J. Exp. Biol. 4, 564-571.

Menzel, R., Backhaus, W., 1991. Colour vision in insects. In: Gouras, P. (Ed.), Vision and Visual Dysfunction. The Perception of Colour. MacMillan Press, London, pp. 262-288.

Monod, T., 1980. Contribution a l'étude des Lotus (Papilionaceae) ouest-sahariens et macaronésiens. Adansonia 19, 367-402.

Mort, M.E., Crawford, D.J., Santos-Guerra, A., et al., 2003. Relationships among the Macaronesian members of Tolpis (Asteraceae: Lactuceae) based upon analyses of inter simple sequence repeat (ISSR) markers. Taxon 52, 511-518.

Oberrath, R., Böhning-Gaese, K., 1999. Floral color change and the attraction of insect pollinators in lungwort (Pulmonaria collina). Oecologia 121 383-391.

Ojeda, I., Santos-Guerra, A., 2011. The intersection of conservation and horticulture: bird-pollinated Lotus species from the Canary Islands (Leguminosae). Biodiv. Conserv. 20, 3501-3516.

Ojeda, I., Santos-Guerra, A., Caujapé-Castells, J., et al., 2012a. Comparative micromorphology of petals in Macaronesian Lotus (Leguminosae) reveals a loss of papillose conical cells during the evolution of bird pollination. Int. J. Plant Sci. $173,365-374$

Ojeda, I., Santos-Guerra, A., Jaén-Molina, R., et al., 2012b. The origin of bird pollination in Macaronesian Lotus (Loteae, Leguminosae). Mol. Phylogenet. Evol. 62. 306-318.

Olesen, J.M., 1985. The Macaronesian bird flower element and its relation to bird and bee opportunists. Bot. J. Linn. Soc. 91, 395-414.
Olesen, J.M., Alarcon, M., Ehlers, B.K., Aldasoro, J.J., Roquet, C., 2012. Pollination, biogeography and phylogeny of oceanic island bellflowers (Campanulaceae) Perspect. Plant Ecol. Evol. Systemat. 14, 169-182.

Ollerton, J., Cranmer, L., Stelzer, R.J., Sullivan, S., Chittka, L., 2009. Bird pollination of Canary Island endemic plants. Naturwissenschaften 96, 221-232.

Paolocci, F., Bovone, T., Tosti, N., et al., 2005. Light and exogenous transcription factor qualitatively and quantitatively affect the biosynthetic pathway of condensed tannins in Lotus corniculatus leaves. J. Exp. Bot. 56, 1093-1103.

Peitsch, D., Fietz, A., Hertel, H., et al., 1992. The spectral input systems of hymenopteran insects and their receptor-based colour vision. J. Comp. Physiol. A $170,23-40$

Proctor, M., Yeo, P., Lack, A., 1996. The Natural History of Pollination. Timber Press, Portland.

Raguso, R.A., 2004. Why do flowers smell? The chemical ecology of fragrancedriven pollination. In: Cardé, R.T., Millar, J.G. (Eds.), Advances in Insect Chemical Ecology. Cambridge University Press, Cambridge, pp. 151-177.

Raguso, R.A., 2008. Wake up and smell the roses: the ecology and evolution of floral scent. Annu. Rev. Ecol. Evol. Systemat. 39, 549-569.

Rausher, M.D., 2008. Evolutionary transitions in flower color. Int. J. Plant Sci. 169 7-21

Raven, P.H., 1972. Why are bird-visited flowers predominantly red? Evolution 26, 674.

Rodríguez-Rodríguez, M.C., Jordano, P., Valido, A., 2013. Quantity and quality components of effectiveness in insular pollinator assemblages. Oecologia, http://dx.doi.org/10.1007/s00442-013-2606-y.

Rodríguez-Rodríguez, C., Valido, A., 2008. Opportunistic nectar-feeding birds are effective pollinators of bird-flowers from Canary Islands: experimental evidence from Isoplexis canariensis (Scrophulariaceae). Am. J. Bot. 95, 1408-1415.

Rodríguez-Rodríguez, M.C., Valido, A., 2011. Consequences of plant-pollinator and floral-herbivore interactions on the reproductive success of the Canary Islands endemic Canarina canariensis (Campanulaceae). Am. J. Bot. 98, 1465-1474.

Sandral, G., Remizova, M.V., Sokoloff, D.D., 2006. A taxonomic survey of Lotus section Pedrosia (Leguminose, Loteae). Wulfenia 13, 97-192.

Schikora, J., Spaethe, J., Brockman, A., Chittka, L., 2002. Colour vision and colour preference in Bombus terrestris: a population biological approach. Zoology 105 28

Scogin, R., Freeman, C.E., 1987. Floral anthocyanins of the genus Penstemon: correlations with taxonomy and pollination. Biochem. Syst. Ecol. 15, 355-360.

Shimada, N., Sasaki, R., Sato, S., et al., 2005. A comprehensive analysis of six dihydroflavonol 4-reductase encoded by a gene cluster of the Lotus japonicus genome. J. Exp. Bot. 56, 2573-2585.

Siveiro, F., Rodríguez-Rodríguez, M.C., 2012. Gallotia galloti (Canary Lizard), Nectarivory. Herpetol. Rev. 43, 333-334.

Skorupski, P., Doering, T., Chittka, L., 2007. Photoreceptor spectral sensitivity in island and mainland populations of the bumblebee, Bombus terrestris. J. Comp. Physiol. A 193, 485-494.

Smith, S.D., Rausher, M.D., 2011. Gene loss and parallel evolution contribute to species difference in flower color. Mol. Biol. Evol. 28, 2799-2810.

Soja, C.M., 1982. Potential contributions of ancient oceanic islands to evolutionary theory. J. Geol. 100, 125-134

Stelzer, R., 2005. Sammelstrategien bei Hummeln ein Vergleich zwischen Insel- und Festlandpopulationen Ralph Stelzer Inhaltsverzeichnis. Universität Würzburg Würzburg.

Streisfeld, M., Rausher, M.D., 2009. Altered trans-regulatory control of gene expression in multiple anthocyanin genes contributes to adaptive flower color evolution in Mimulus aurantiacus. Mol. Biol. Evol. 26, 433-444.

Tanaka, Y., Sasaki, N., Ohmiya, A., 2008. Biosynthesis of plant pigments: anthocyanins, betalains and carotenoids. Plant J. 54, 733-749.

Valido, A., Dupont, Y.L., Hansen, D.M., 2002. Native birds and insects, and introduced honey bees visiting Echium wildpretii (Boraginaceae) in the Canary Islands. Acta Oecol.: Int. J. Ecol. 23, 413-419.

Valido, A., Dupont, Y.L., Olesen, J.M., 2004. Bird-flower interactions in the Macaronesian islands. J. Biogeogr. 31, 1945-1953.

Valido, A., Olesen, J.M., 2010. Pollination on islands: examples from the Macaronesian archipelagos. In: Serrano, A.R.M., Borges, P.A.V., Boieiro, M., Oromí, P. (Eds.), Terrestrial Arthropods of Macaronesia. Biodiversity, Ecology and Evolution. Sociedade Portuguesa de Entomologia, Lisboa, pp. 249-283.

Vogel, S., Westerkamp, C., Thiel, B., Gessner, K., 1984 . Ornithophilie auf den Canarischen Inseln. Plant Systemat. Evol. 146, 225-248.

Weiss, M.R., 1995. Floral color change: a widespread functional convergence. Am. J. Bot. 82, 167-185

Whitney, H.M., Chittka, L., Bruce, T.J.A.M., Glover, B.J., 2009. Conical epiderma cells allow bees to grip flowers and increase foraging efficiency. Curr. Biol. 19 948-953.

Whitney, H.M., Poetes, R., Steiner, U., Chittka, L., Glover, B.J., 2011. Determining the contribution of epidermal cell shape to petal wettability using isogenic antirrhinum lines. PLoS ONE 6, e17576.

Whittaker, R.J., Fernández-Palacios, J.M., 2007. Island Biogeography: Ecology, Evolution, and Conservation. Oxford University Press, Oxford.

Willmer, P., Stanley, D.A., Steijven, K., Matthews, I.M., Nuttman, C.V., 2009. Bidirectional flower color and shape changes allow a second opportunity for pollination. Curr. Biol. 19, 919-923.

Zufall, R.A., Rausher, M.D., 2003. The genetic basis of a flower color polymorphism in the common morning glory (Ipomoea purpurea). J. Hered. 94, 442-448. 